\title{
Erratum to: The secondary-tertiary transition viewed as a change in mathematical cultures: an exploration concerning symbolism and its use
}

\author{
Claudia Corriveau ${ }^{1} \cdot$ Nadine Bednarz $^{2}$
}

Published online: 20 May 2017

(C) Springer Science+Business Media Dordrecht 2017

\section{Erratum to: Educ Stud Math 95, 1-19 (2017) \\ DOI 10.1007/s10649-016-9738-z}

The following publication was missing from the Reference list:

Robert, A. (1998). Outils d'analyze des contenus mathématiques à enseigner au lycée et à l'université [Tools to analyze mathematical contents being taught in high school and university]. Recherches en didactique des mathématiques, 21(1-2), 57-80.

The online version of the original article can be found at http://dx.doi.org/10.1007/s10649-016-9738-z

Claudia Corriveau

claudia.corriveau@fse.ulaval.ca

1 Faculté des Sciences de l'Éducation, Professor at Université Laval, 2320 rue des Bibliothèques (bur.1230), Québec QC G1V 0A6, Canada

2 Département de Mathématiques, Université du Québec à Montréal, C.P. 8888, Succursale Centre-ville (PK-5151), Montréal QC H3C 3P8, Canada 